\title{
A systemic framework for managing e-learning adoption in campus universities: individual strategies in context
}

Carol Russell*

Faculty of Engineering, University of New South Wales, Sydney, Australia

(Received 23 June 2008; final version received 6 August 2008)

There are hopes that new learning technologies will help to transform university learning and teaching into a more engaging experience for twenty-first-century students. But since 2000 the changes in campus university teaching have been more limited than expected. I have drawn on ideas from organisational change management research to investigate why this is happening in one particular campus university context. My study examines the strategies of individual lecturers for adopting e-learning within their disciplinary, departmental and university work environments to develop a conceptual framework for analysing university learning and teaching as a complex adaptive system. This conceptual framework links the processes through which university teaching changes, the resulting forms of learning activity and the learning technologies used - all within the organisational context of the university. The framework suggests that systemic transformation of a university's learning and teaching requires coordinated change across activities that have traditionally been managed separately in campus universities. Without such coordination, established ways of organising learning and teaching will reassert themselves, as support staff and lecturers seek to optimise their own work locally. The conceptual framework could inform strategies for realising the full benefits of new learning technologies in other campus universities.

Keywords: e-learning adoption; complex adaptive systems; campus universities

\section{Context}

Since 2000 several studies in the UK, Australia and New Zealand have shown that the benefits of e-learning have not been reaching mainstream learning and teaching in campus universities (Bell et al. 2002; Marshall 2005; Sharpe et al. 2006). This has disappointed expectations that learning technologies would enable universities to adapt to a context of changed student needs (Department of Education, Science and Training (DEST) 2002; Harvey and Beards 2004; Higher Education Funding Council for England (HEFCE) 2005; Scottish Funding Council (SFC) 2006). Surveys suggest that campus universities lack coordinated strategies for use of new online learning technologies, and are relying on emergent local initiatives (Organisation for Economic Cooperation and Development (OECD) 2005). In the University of New South Wales (UNSW) in Australia, a quality audit report commented on such a lack of coordination (Australian Universities Quality Agency (AUQA) 2006).

*Email: carol.russell@unsw.edu.au 
UNSW is a metropolitan campus-based university with 40,000 students, which has major research and teaching activities in business, medicine, engineering and the applied sciences. UNSW is one of the Group of Eight (Go8) that identify themselves as 'Australia's leading universities' and in which campus-based study is the norm, especially at undergraduate level. UNSW is also a member of the Universitas 21 (U21) international network of 'leading research-intensive universities'.

At UNSW, use of the institutional online learning management system, both in terms of numbers of courses with an online presence and in terms of student enrolments in these courses, has been increasing steadily at over $30 \%$ a year since 2000 . However, as in other campus universities, the online environment is primarily used for delivering lecture notes and administrative information. As part of a strategy for promoting innovative teaching using new learning technologies, UNSW introduced the Innovative Teaching and Educational Technology (ITET) Fellowships, a cross-discipline initiative involving a total of 75 staff in five six-month-long full-time Fellowship programmes between 2001 and 2006. The core data for this study came from one of these ITET cohorts: 19 staff from a spread of disciplines, who were keen to introduce innovations into their own teaching contexts. The Fellowship programme activities and outcomes are described elsewhere (Russell 2005; Russell and Lee 2005). In this paper I draw on work carried out for a PhD thesis (Russell 2008), in which I used complex adaptive systems theories of organisation to analyse individual strategies for adopting e-learning technologies in the UNSW context.

\section{The university as a complex adaptive system}

Universities have been described as 'supercomplex' (Barnett 2000). One aspect of this complexity is diversity, both in the relationships between disciplinary knowledge and disciplinary organisation (Becher and Trowler 2001) and in how disciplinary knowledge, teaching and learning are perceived in relation to each other (Meister-Scheytt and Scheytt 2005; Robertson and Bond 2005).

There is a growing body of management literature that draws on concepts from evolutionary biology and from physical sciences to develop models of complex organisational change processes. By viewing the university as a living adaptive system we can build an integrated understanding of individual lecturers' decisions, their organisational context and the material learning technologies they use (including everything from books and blackboards to Web 2.0 e-learning tools); rather than dividing our understanding into separate areas of expertise.

The structure of living systems and their actual (material) components are complementary yet distinct aspects of any biological explanation: they complement each other reciprocally but cannot be reduced to one another. (Varela and Maturana 1972)

Figure 1 shows how the same basic organisational principles might apply to a university learning and teaching system. Processes of growth, learning and change interact with the forms of learning and teaching, and with material learning technologies and resources (including physical and virtual learning spaces). Following Capra (2002), I use a 3D tetrahedral shape as a building block for models at different organisational levels (individual, department and university). The edges and faces of the tetrahedron can represent particular research perspectives - the interplay of technology and forms of learning activity for example. 


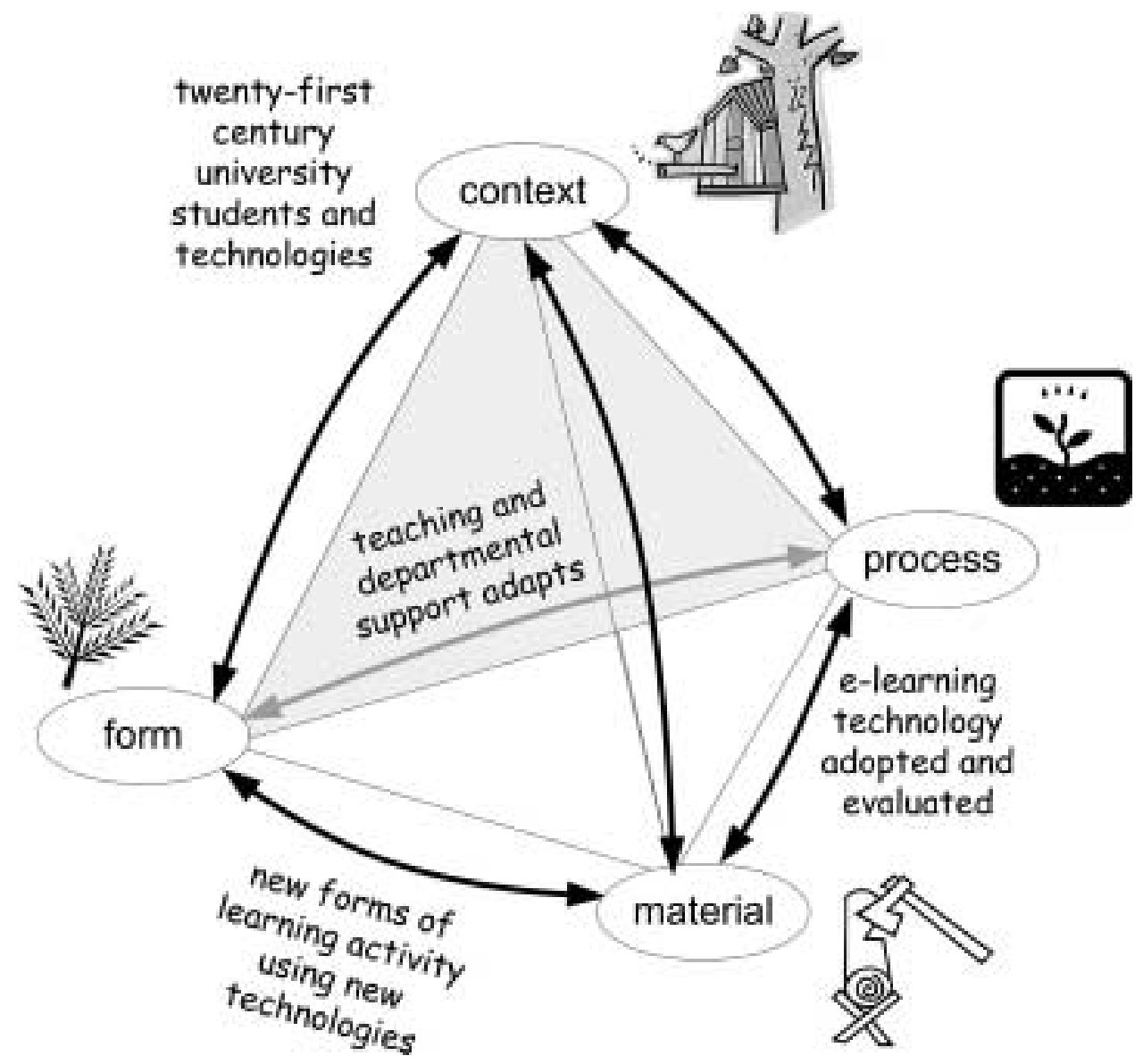

Figure 1. A conceptual framework for modelling university learning and teaching systems, including the role of material technologies.

Capra (2002) suggests that complex adaptive systems theory is not just a biological analogy for organisations, but represents the fundamental properties of all complex systems, and can therefore be used as a rigorous model.

\section{Modelling complexity and complementarities}

Complexity theories have been developed as rigorous modelling methods to gain understanding of different aspects of organisational change. Mathematical modelling based on game theory takes into account the decisions of individuals and departments, as they each aim to optimise their own conditions locally.

These mathematical studies show that in any human organisation that is sufficiently complex to have local decision-making and optimisation, there will be interdependent activities, called complementarities. For the organisation to continue functioning as a whole, change in one of these complementarities needs to be coordinated with change in the others. Change that is coordinated across the organisation's key complementarities will always give a better result than piecemeal change. An 
example is the benefit to computer users of focusing on one or two standards, so as to ease the development of complementary operating systems, applications and hardware. Any standard is better than none.

The idea of complementarities was initially applied to explain the transition from mass manufacturing to flexible manufacturing systems (Milgrom and Roberts 1995). Later research, across many different types of organisation, provides further empirical evidence supporting the mathematical prediction that complementarities will be found in any large complex and diverse human organisation (Pettigrew et al. 2003). If university learning and teaching is more like complex organic life than like a machine, simplistic mechanistic models for 'engineering' change will not account for complex internal organisational interdependencies (Kezar 2001).

However, this raises a practical problem. Models are maps, simplified representations of significant aspects of a complex reality. Any model that fully reflects the complexity of a system would be as difficult to understand as the system itself. It is therefore better to work with a simple model where the limitations are explicit than to attempt to use a detailed and complex one (Cilliers 2001). How do we know what simplifications we can make to navigate successfully through technology-supported change in a university learning and teaching system without missing important interdependencies?

\section{Complexity and diversity in university learning and teaching}

Empirical research on one European university's response to government higher education reforms suggests that universities are complex self-referential organisations in which defensive routines are widespread. The authors suggest that the culture is quasi-familial, with mental models and maps that are 'unspoken and inexpressible' and that management should not aim to dissolve paradoxes, or reduce (cognitive) complexity, but should aim to open up alternative ways of thinking and acting. (Meister-Scheytt and Scheytt 2005).

Individual staff development is one way of opening up new ways of thinking, but staff development on its own has had limited impact as a national strategy for transforming university learning and teaching in the UK (HEFCE 2005). There are reports that staff development initiatives offered by educational specialists are largely failing to connect with university teaching practice (Trigwell and Shale 2004). Knowledge about learning technology innovation is not spreading as fast as expected (Hannafin and Kim 2003; Oliver 2005) and as a result teaching practices have been failing to keep up with student expectations (Oblinger 2005).

Communities of practice have been advocated as a less formal way of developing and spreading new knowledge about technologies and teaching (Allan and Banks 2003; Bell 2003; Hunter 2003), but there are questions about whether communities of practice as defined by Wenger are either achievable or necessary (Wenger, McDermott, and Snyder 2002; Eraut 2002).

Academic disciplinary communities each have their own knowledge creation processes and forms of organisation (Becher and Trowler 2001). There are also disciplinary differences in learning technology use (Russell 2005). Complex adaptive systems models of organisations suggest that this internal diversity will enhance a university's ability to adapt, but only if there are networks to link up the diverse perspectives, creating distributed cognition (van Fenema 2005). Rational allocation of resources, on the other hand, acts to reduce diversity (Andriani 2001). Some writers 
on complexity in organisations focus on self-organisation, questioning the viability of intentional management and giving reasons why change cannot be managed (Griffin, Shaw, and Stacey 1999; Stacey 2005). In most universities, however, accountability for use of public funding requires both rational allocation of resources and intentional management of change.

Individual lecturers' strategies are shaped by informal social systems and they are also facilitated or constrained by formal organisation. The concept of the learning organisation can encompass both formal and informal, through individual and team learning to change mental models, 'the images, assumptions and stories which we carry in our minds of ourselves, other people, institutions and every aspect of the world' (Senge et al. 1994, 235). This systemic approach allows for the integration of multiple perspectives - formal and informal organisation, individual and social learning, and most importantly for this study human and technological systems.

In a university, individuals each have a different perspective on the organisation, because of their different academic or professional disciplines or their different organisational roles. The research I carried out in UNSW aimed to combine different individual perspectives on adoption of new learning technologies, in order to identify systemic patterns across the university's learning and teaching activities as a whole.

\section{Research methodology and methods}

The research in UNSW arose initially from a need to evaluate the effectiveness of the ITET Fellowship programme in transforming learning and teaching systems. Guided by examples from comparable higher education and change management research contexts (Zuber-Skerritt 1992; Eden and Huxham 1996; Salmon 2001), I adopted an action research approach.

In their research into socio-technical organisational change, the London School of Economics complexity research team used an action research methodology involving different types of data. They advocate gathering data from individuals and from groups, including both verbal and visual representations, the articulation of which contributes to the change process - 'To use the language of complexity, when individual agents change their patterns of interaction new structures or new properties emerge' (Mitleton-Kelly 2003, 60). The INNFORM project, which applied complexity theories in large-scale empirical research into innovative forms of organisation, also adopted a multi-method approach (Pettigrew et al. 2003).

At the beginning of my research, I relied primarily on analysis of textual data from group discussions, interviews and questionnaires. However, as the research progressed, I extended the range of data collection methods to visual representations, and in particular cognitive mapping.

\section{Action research phases}

The first phase of my action research involved collecting and analysing textual data from discussions among the ITET Fellows, and their written comments about how the Fellowship was influencing their strategies for use of learning technologies. Thematic analysis of the text identified a large number of themes and sub-themes related to disciplinary and organisational influences on the Fellows' strategies. But the text analysis did not clarify how the Fellows were linking these themes. 
The early Fellowship programmes had elements of staff development, and included formal presentations on educational theory by specialists. Codified knowledge (theory), in the form of research papers and conferences, policies and guidelines, can be transferred between contexts and teams, whereas tacit knowledge is shared only when people work together (Edmondson et al. 2003). Codified knowledge also allows teachers to predict and plan. But analysis of the discussions and direct feedback from participants showed that they often rejected codified educational knowledge as 'a party line' (Russell 2003), preferring to focus on experiential and disciplinespecific knowledge. This response is consistent with reports on the difficulties of introducing codified educational knowledge into university classroom teaching, because of its reliance on tacit and discipline-specific teaching strategies (Trowler and Cooper 2002; Fanghanel 2004; Perkins 2006).

The fourth ITET programme therefore emphasised support for the development of shared knowledge within a cross-discipline community of practice (Russell and Lee 2005).

In the second and third phases of the action research, I asked the Fellows from the fourth ITET programme to create visual representations, in the form of cognitive maps of their strategies for using e-learning, before and after the Fellowship programme.

In the final phase of the action research, I analysed the cognitive maps for patterns, and related these to evidence of change in the broader learning and teaching practices and support systems across the university, and the role of ITET Fellows in bringing about these changes.

\section{Cognitive mapping}

Cognitive mapping has been developed as a way of eliciting and developing strategy in organisations (Eden and Ackermann 1998) and there is specialist software for creating, editing and analysing patterns in the resulting maps. Cognitive maps are appropriate for eliciting lecturer strategies for using e-learning technologies for the following reasons:

(1) The maps are a visual representation, more suitable than (linear) spoken or written text for representing the multiple influences in individual thought and action.

(2) The participants can articulate and think through complex tacit connections during the interview. So the interview itself helps to develop and clarify strategies for using educational technology, by making the tacit connections explicit.

(3) The mapping process allows for exploration and recording of the connections between the participants' disciplinary knowledge, their departmental context and their use of educational technology.

I collected maps from each of the 19 participants, who represented a mix of disciplines and roles, before and after the ITET Fellowship programme. This provided two snapshots of the various strategies across the group - the motivations and constraints for using learning technologies in their teaching. Figure 2 shows one example of the cognitive maps, in which all the concepts and their categorisation and linking are defined by the participant during an interview. The interview and map analysis methods are documented in detail elsewhere (Russell 2008, Ch.5). 


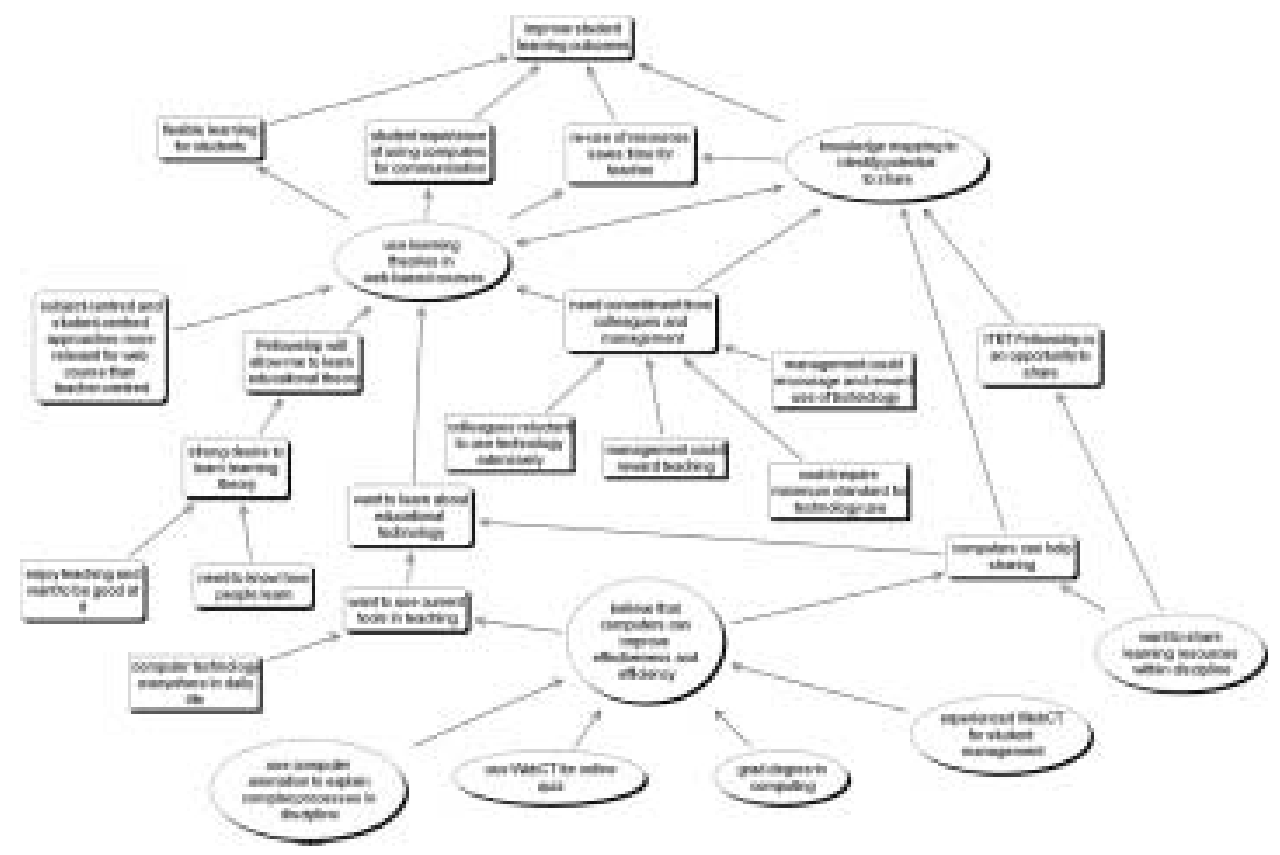

Figure 2. A cognitive map of a strategy for adopting e-learning (shapes indicate concept categories).

\section{Results and interpretation}

\section{Patterns found in cognitive maps}

I analysed the cognitive maps for concept link patterns corresponding to themes identified from the research literature on educational technology and from the thematic analysis of text from the first action research phase.

\section{Discipline-related patterns}

Pre-ITET, there are patterns of discipline-based difference in strategies for the use of educational technology - for example with those from soft applied disciplines such as social science had different patterns in their use of technology to those from hard applied disciplines such as engineering (Becher and Trowler 2001). PostITET, these differences are no longer discernable. Some of the pre-ITET strategy patterns appear more widely within the group post-ITET; while others disappear. Discipline-specific beliefs about learning and teaching disappear post-ITET, and disciplinary learning experiences are reframed as part of a broader educational knowledge. This provides some evidence that participation in a cross-discipline group can increase the range of strategies available to academics when they adopt educational technology.

\section{Move from individual to team focus}

Pre-ITET strategies focus on individual concern for meeting students' needs. Post-ITET, there are more strategies for working with others, in a departmental or cross-discipline 
environment, to improve student learning. This is evidence that the Fellowship led to strategies that are less individualistic, relate more to department and institutional contexts and take more advantage of opportunities for cross-discipline collaboration and support.

\section{Motivation, confidence and constraints}

The ITET Fellows are intrinsically motivated to use new technologies to improve learning and teaching. Post-ITET, they are more aware of extrinsic motivators, such as external recognition of teaching, and support for planning of individual workloads. They have also become more confident in influencing curriculum development. This is evidence that building shared educational knowledge that is explicit (codified) and externally acknowledged, within a cross-discipline community empowers the individual teachers to make changes to learning and teaching systems and curricula in association with their use of e-learning technology.

Coexisting with this increased confidence in the post-ITET strategies are assumptions that research will continue to be valued more than teaching; along with continuing concerns about being able to find support, resources and time for developing learning and teaching. The post-ITET maps include strategies for dealing these constraints.

\section{Organisational data}

To place the individual lecturer strategies in an organisational context, I triangulated it with other types of data on responses to e-learning within UNSW:

- interviews and cognitive mapping with a traditional classroom teacher who does not use e-learning;

- published accounts of the development of Omnium, an e-learning innovation that has been funded and supported as disciplinary research;

- statistical reports on the uses of learning technologies across UNSW;

- accounts (interviews and publications) of developments in one discipline area where there have been some systemic changes in learning and teaching;

- analysis of the formal roles held by ITET Fellows across UNSW;

- an interview with the UNSW senior manager responsible for the ITET programme.

The information from each of these is summarised next, with comments.

\section{Lecturer perspectives}

The traditional university lecturer, like the ITET Fellows, was intrinsically motivated to help students learn, but reported feeling isolated and discouraged by the departmental context. This account exemplifies some of the constraints on innovation by individual teachers in a research-focused campus university environment. Without extrinsic motivation and support for teaching work, this lecturer was left to develop practices and theories by trial and error over many years.

This gives another perspective on reports in the higher education literature of the lack of connection between mainstream classroom practice in traditional campus 
universities and either educational theory or the opportunities afforded by elearning. Teachers either respond to departmental priorities and focus on disciplinary research rather than innovative teaching, or follow their intrinsic motivation as teachers unsupported by colleagues - developing tacit knowledge that they are reluctant to abandon in favour of theories from educational experts outside the discipline.

\section{Discipline-specific innovation}

UNSW's College of Fine Arts invested in the development of Omnium, an online environment for design studies. The software environment has been used for a number of innovative international distance learning projects. However, the Omnium project overall is presented as disciplinary research. The Omnium environment is not integrated into the UNSW online learning management system and is therefore not available as a mainstream service for UNSW students.

Each discipline has its own approaches to learning and teaching. Where an innovation is well adapted for one disciplinary environment, there is reluctance to make the effort to adapt the innovation for other disciplines - especially when recognition for the innovation is based upon an international discipline-specific community rather than a cross-discipline local one. Therefore, even when an academic department has supported development of an innovative learning technology, the research focus has limited its application across the university.

\section{Institutional use of learning technologies}

Most UNSW students are experiencing e-learning technology that primarily supports traditional learning methods. Nevertheless some technological tools are beginning to involve teachers in more active use of the online environment to shape the nature of student learning: similarity detection tools, library systems, information literacy support and mathematical modelling tools. Students are demanding more digital lecture recordings and podcasts, and some lecturers are now beginning to use these recordings to review their own lectures; effectively opening up the classroom to reflective teaching practice and linking it to the online environment.

Learning technologies are becoming part of a change process - through mutual adjustments that involve students and technologies as much as through the actions of lecturers.

\section{School and faculty}

In the Faculty of Science, the School of Physics was finding it difficult to engage first year students in traditional recipe-type laboratory activities (Wilson and Russell 2003). Classes are large and involve organised teams of tutors and academics. Previous attempts to introduce innovations, even lab refurbishments, had changed little. One of the two ITET Fellows in the school used an online diary to gather detailed evidence on the student experience in the labs. The other helped to develop Web-based support for lab work. When funding became available for a new lab building, conditional upon an educational rationale, the Fellows were able to provide evidence and practical solutions for the introduction of first-year lab projects, and for the new flexible lab spaces 
and technologies to support this. The lab space, the projects and the required academic and tutor support systems are now well established.

The funding criteria for the new lab came from the dean of the faculty. ITET Fellows also organised themselves at the faculty level to set up formal support for learning and teaching. This is an example of complementarities spanning different levels of organisation - community, department, faculty and institution. Systemic change involved support from the institutional context that acted simultaneously upon the forms of learning and teaching, the processes of evaluating learning and teaching and the material facilities used for learning and teaching within the school (Figure 3).

Another UNSW faculty, of a similar size and with a similar number of ITET Fellows, had no corresponding organised support in the faculty and showed no such systemic changes.

\section{Formal organisational roles and changes}

The ITET Fellows have a higher than average representation as staff in positions of formal influence on strategy, policy and teaching practice. This representation covers core job functions (e.g. heads of schools, programme coordinators, associate deans) and membership of UNSW's policymaking committees.

This illustrates the interplay of formal and informal processes. The crossdiscipline community is able to identify systemic issues that are not apparent from

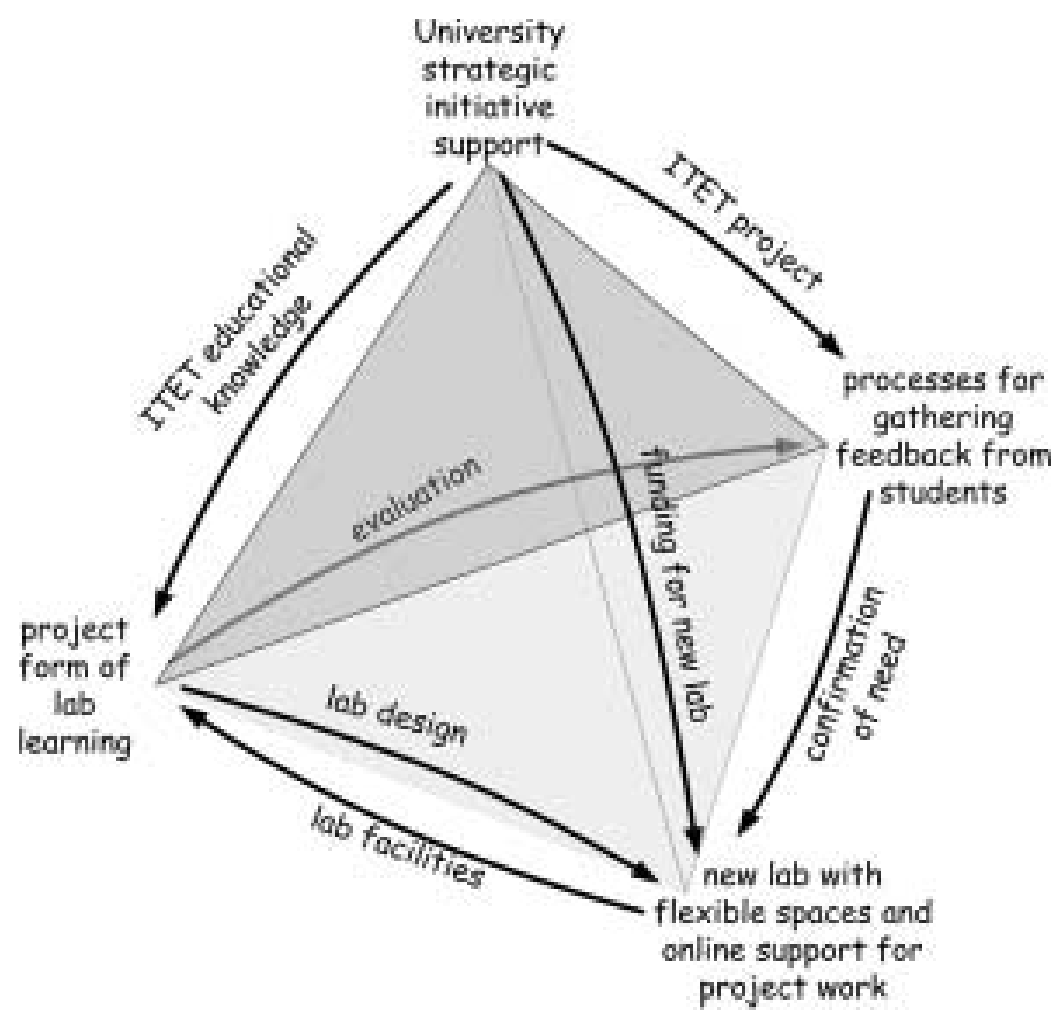

Figure 3. Changes in the UNSW School of Physics. 
one disciplinary perspective, such as a need for extrinsic motivation through recognition of teaching. The community members' formal organisational roles provide opportunities for changing university systems, for example to introduce more formal recognition and support for teaching.

\section{Institutional strategic leadership}

Before 2000, UNSW had nobody on its senior management team with specific responsibility for learning and teaching. In 2000, an experienced senior academic with credibility both as a researcher and as a teacher took on a new Pro Vice Chancellor (PVC) role and successfully argued for strategic funding for a package of initiatives that included the ITET Fellowship. In discussions with the ITET Fellows, the PVC was alerted to a number of institutional factors, including UNSW's internal funding structures and promotion processes, which were hindering change in learning and teaching.

Senior managers, like everyone else in the organisation, have only a partial understanding of the whole university system. In this case one senior manager not only formally sponsored the ITET community as a strategic initiative, but also participated actively in its discussions. This gave it a voice and an influence on institutional policies and systems that an entirely informal self-organising community may not have had.

\section{A postscript}

In 2006 the PVC who was the main sponsor of the ITET Fellowship retired. A new Vice Chancellor took office and restructured the UNSW senior management team, with restructured portfolios. In 2006, the new Vice Chancellor identified strategic goals for the institution as a research-focused university in which all academic staff were required to be research-active, and in which the proportion of non-academic staff was to be reduced (Hilmer 2006). However, by October 2007, UNSW had shown further improvements in external indicators of learning and teaching quality, including the CEQ, ranking third nationally and outperforming all other Go8 universities (UNSW 2007). The additional funding resulting from government rewards for improved learning and teaching outcomes has been allocated to further developments at the institutional level, including investment in e-learning and funding for Learning and teaching fellow posts in each faculty, who will work both in their own disciplines and as a cross-discipline group. There has been a systemic shift in learning and teaching, some aspects of which may be irreversible.

\section{A systemic overview}

Figure 4 shows a systemic overview of influences on lecturer strategies in UNSW, in the form of an annotated influence diagram based on the cognitive map analysis results, triangulated with organisational data. Arrows indicate positive influences between binary concepts (in the form $x \ldots$ rather than $y$ ). In each concept the first part represents a component of the systemic change required for effective use of new learning technologies. The second part of each concept represents the corresponding component of the traditional campus university learning and teaching system that will hinder change if left in place. 


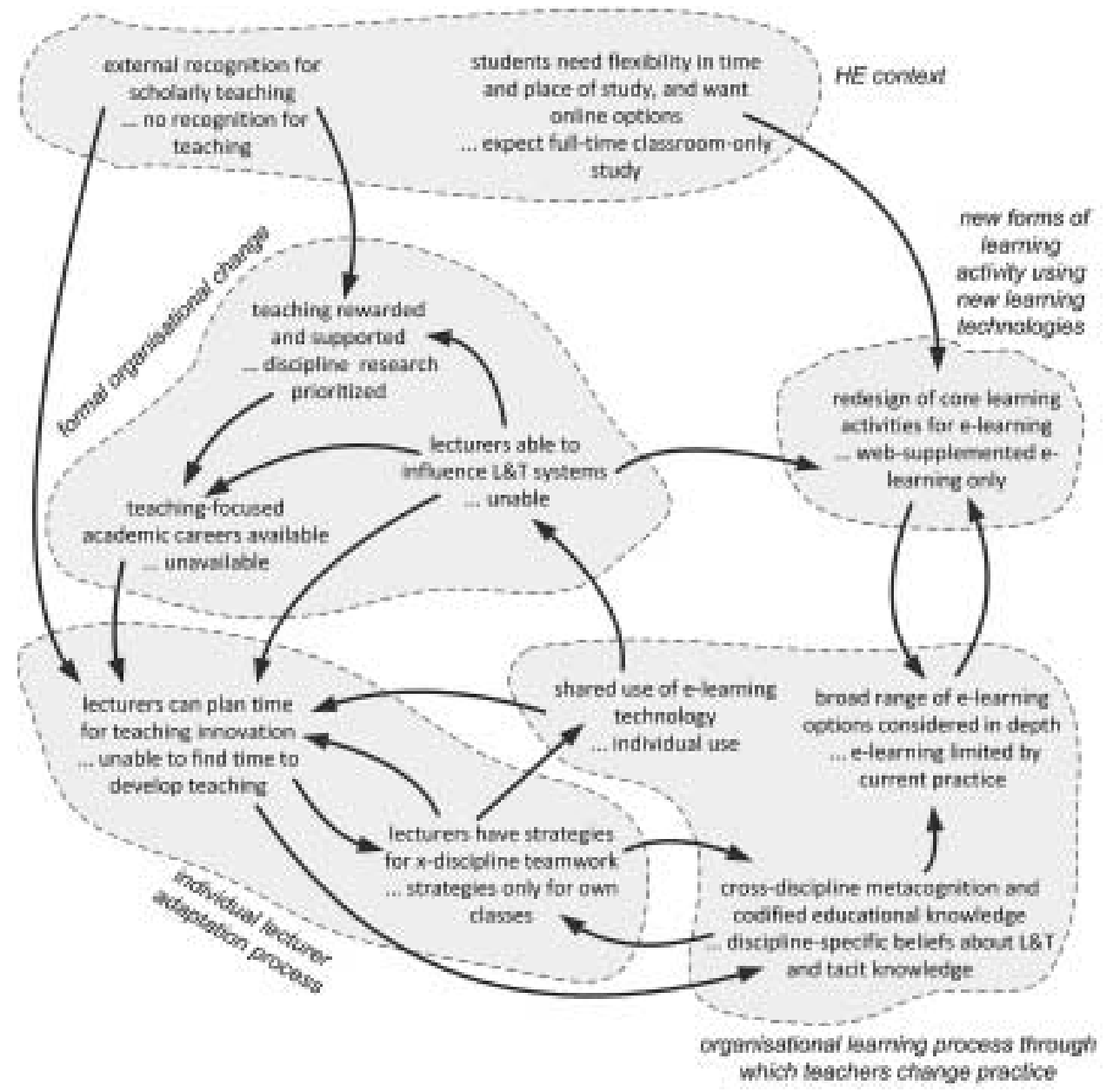

Figure 4. Contextual influences on individual teachers' strategies in UNSW.

Figure 5 places these influences in the tetrahedral framework. Time and support for academic participation in cross-discipline networks is a key process for enabling new forms of learning activity using new technologies.

\section{Discussion and conclusions}

UNSW is typical of many established campus universities where the majority of academics are still using traditional disciplinary face-to-face methods, and where research often takes priority over teaching in academic work. The UNSW study found some systemic patterns that influence the adoption and integration of e-learning, which have implications for the integration of new learning technologies in similar campus universities.

A survey of 21 Australian universities (Uys, Buchan, and Ward 2006) found that only a third have any mainstream-funded support available for developing online learning resources. Two-thirds have limited support for e-learning development or 


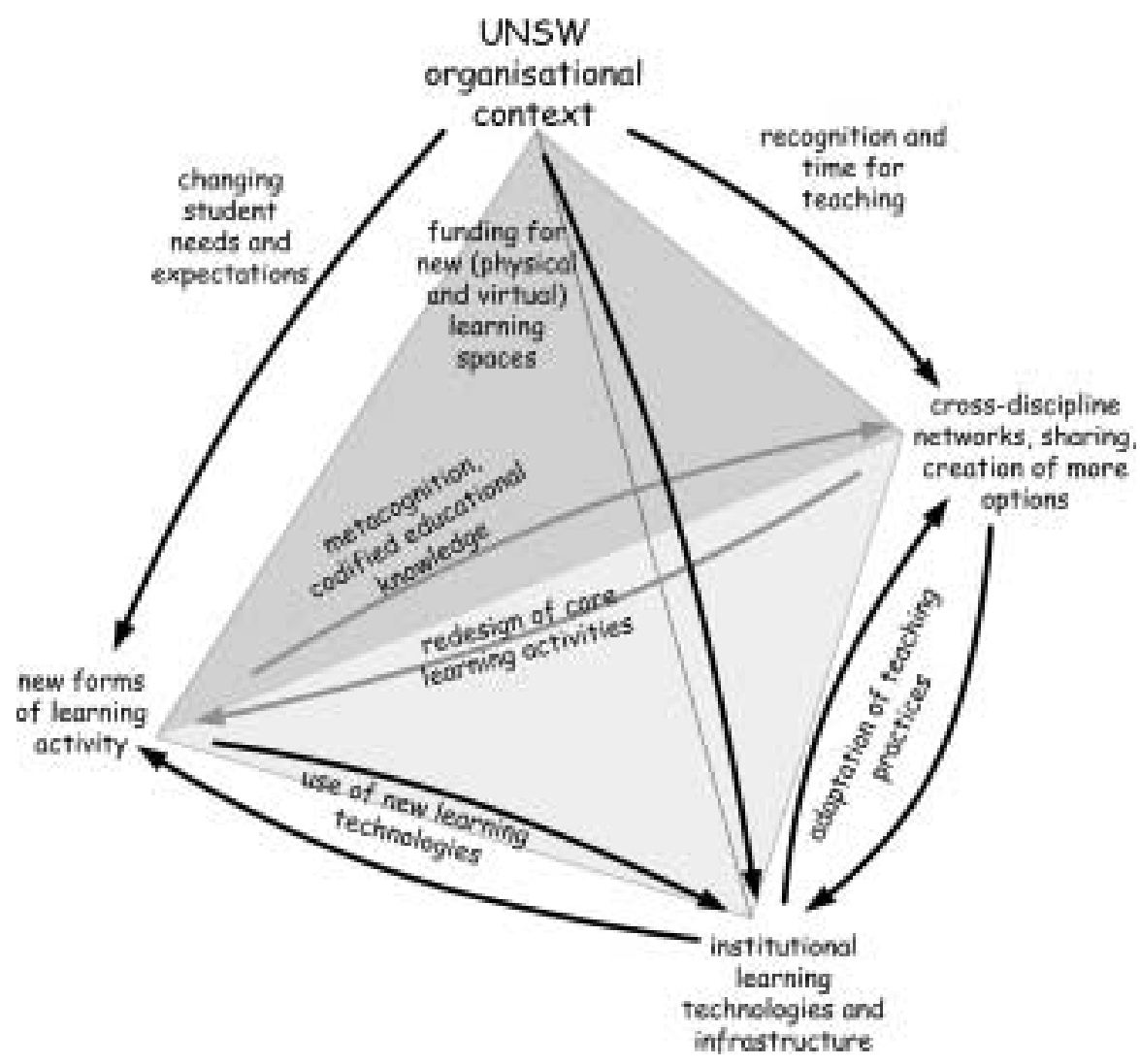

Figure 5. Model of the changing UNSW learning and teaching system.

none at all, and are relying on academics to do it for themselves. In campus universities, decisions about use of e-learning technology are typically being made by individual lecturers. This dearth of support services is both a symptom and a cause of the slow adoption of new learning technologies.

Complexity theory explains why cross-discipline networking is an essential component of the process of adaptation. It increases the diversity of options available to lecturers who are seeking to introduce technology-supported innovations into their teaching. Once new forms of learning activity are articulated and shared, they become part of codified organisational knowledge, which can be embedded in forms of organisation support and embodied in the associated material resources and facilities - policy guidelines, funding for support services, virtual and physical learning spaces. By analysing cognitive maps from the same people before and after a cross-discipline experience, and collating data on the corresponding institutional changes, I have been able to illustrate this process in one campus university context.

Complexity theory also implies that sustainable change involves organisational complementarities. The ITET programme and the research with its participants identified some key complementarities in the UNSW learning and teaching system. These act between organisational levels, as shown in Figures 3-5; clarifying why staff development for individuals, on its own, is not enough to bring about change. Figure 6 illustrates how the tetrahedral framework might provide a starting point for 


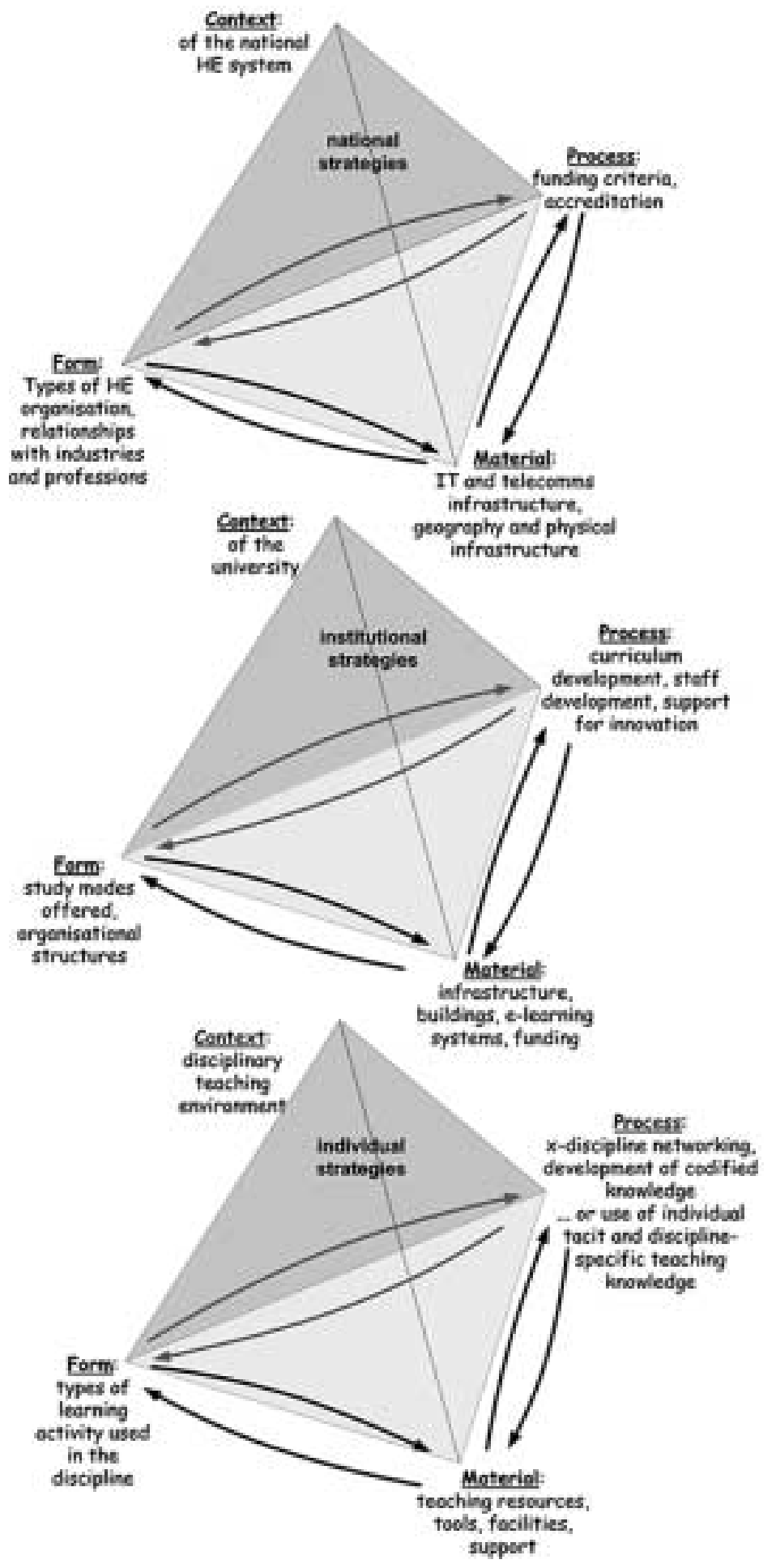

Figure 6. National, institutional and disciplinary influences on e-learning adoption. 
identifying complementary components of university learning and teaching strategy, including the role of learning technologies, at individual, institutional and national levels.

This conceptual framework and the research methodology described here could be applied in other universities, to guide a systemic approach to adoption of new learning technologies. However, further research in other contexts is needed to validate the broader applicability of this approach.

\section{Acknowledgements}

I thank Professor Gilly Salmon, University of Leicester, for her supervision of the $\mathrm{PhD}$ research upon which this paper is based, my colleagues at UNSW for providing the data, and the anonymous reviewers for suggesting some improvements to the original submission.

\section{References}

Allan, B., and S. Banks. 2003. Developing a learning community into a community of practice. Paper presented at the Association for Learning Technology Conference, September 7-9, in Sheffield, UK.

Andriani, P. 2001. Diversity, knowledge and complexity theory: Some introductory issues. International Journal of Innovation Management 5, no. 2: 257-74.

AUQA. 2006. Report of an audit of the University of New South Wales. Melbourne, Australia: Australian Universities Quality Agency.

Barnett, R. 2000. Realizing the university in an age of supercomplexity. Buckingham, UK: Society for Research into Higher Education and Open University Press.

Becher, T., and P.R. Trowler. 2001. Academic tribes and territories. 2nd ed. Buckingham, UK: Society for Research into Higher Education and Open University Press.

Bell, F. 2003. Framing e-learning communities within a wider context. Paper presented at Association for Learning Technology Conference, September 7-9, in Sheffield, UK.

Bell, M., D. Bush, P. Nicholson, D. O’Brien, and T. Tran. 2002. Universities online: A survey of online education and services in Australia. Canberra, Australia: Department of Education Science and Training.

Capra, F. 2002. The hidden connections. London: HarperCollins.

Cilliers, P. 2001. Boundaries, hierarchies and networks in complex systems. International Journal of Innovation Management 5, no. 2: 135-47.

DEST. 2002. Striving for quality: Learning, teaching and scholarship. Canberra, Australia: Department of Education, Science and Training.

Eden, C., and F. Ackermann. 1998. Making strategy: The journey of strategic management. London: Sage.

Eden, C., and C.Y. Huxham. 1996. Action research for management research. British Journal of Management 7: 91-95.

Edmondson, A.C., A.B. Winslow, R.M.J. Bohmer, and G.P. Pisano. 2003. Learning how and learning what: Effects of tacit and codified knowledge on performance improvement following technology adoption. Decision Sciences 34, no. 2: 197-223.

Eraut, M. 2002. Conceptual analysis and research questions: Do the concepts of 'learning community' and 'community of practice' provide added value? Paper presented at the Annual meeting of the American Educational Research Association, April 1-5, in New Orleans, LA, USA.

Fanghanel, J. 2004. Capturing dissonance in university teacher education environments. Studies in Higher Education 29, no. 5: 575-90.

Griffin, D., P. Shaw, and R. Stacey. 1999. Knowing and acting in conditions of uncertainty: A complexity perspective. Systemic Practice and Action Research; New York 12, no. 3: 295-309.

Hannafin, M.J., and M.C. Kim. 2003. In search of a future: A critical analysis of research on web-based teaching and learning. Instructional Science 31: 347-51.

Harvey, B., and D. Beards. 2004. E-learning in Scottish further and higher education. Education \& Training 46, nos. 6/7: 353-60. 
HEFCE. 2005. Summative evaluation of the Teaching Quality Enhancement Fund (TQEF): A report to HEFCE by the Higher Education Consultancy Group and CHEMS Consulting. London: HEFCE.

Hilmer, F. 2006. Vice Chancellor's address to a University of New South Wales staff meeting. July 2006, in Sydney, Australia.

Hunter, B. 2003. Building learning communities to embed the use of learning technologies in a research led university. Paper presented at Association for Learning Technology Conference, September 7-9, in Sheffield, UK

Kezar, A. 2001. Higher education models of change: Examination through the typology of six models. In ASHE-ERIC higher education report, 79-112. Washington, DC: ASHE-ERIC.

Marshall, S. 2005. Determination of New Zealand tertiary institution e-learning capability: An application of an e-learning maturity model: Report on the e-learning maturity model evaluation of the New Zealand tertiary sector. Wellington, New Zealand: University Teaching Development Centre, Victoria University of Wellington.

Meister-Scheytt, C., and T. Scheytt. 2005. The complexity of change in universities. Higher Education Quarterly 59, no. 1: 76-99.

Milgrom, P., and J. Roberts. 1995. Complementarities and fit: Strategy, structure and organizational change in manufacturing. Journal of Accounting and Economics 19: 179-208.

Mitleton-Kelly, E. 2003. Complexity research - approaches and methods: The LSE Complexity Group integrated methodology. In Organizational complexity (vol. 2003/6), ed. A. Keskinen, M. Aaltonen, and E. Mitleton-Kelly, 56-77. Helsinki, Finland: Tutu Publications, Finland Futures Research Centre.

Oblinger, D.G. 2005. Learners, learning and technology: The Educause learning initiative. Educause Review 40, no. 5. http://connect.educause.edu/Library/EDUCAUSE+Review/ EDUCAUSEReviewMagazineVol/40585

OECD. 2005. E-learning in tertiary education. Paris: Organisation for Economic Co-operation and Development.

Oliver, R. 2005. Ten more years of educational technologies in education: How far have we travelled? Australian Educational Computing 20, no. 1: 18-23.

Perkins, D. 2006. Constructivism and troublesome knowledge. In Overcoming barriers to student understanding - threshold concepts and troublesome knowledge, ed. J.H.F. Meyer, and R. Land. London: Routledge.

Pettigrew, A.M., R. Whittington, L. Melin, C. Sanchez-Runde, F.A.J. van-den-Bosch, W. Ruigrok, and T. Numagami. 2003. Innovative forms of organizing: International perspectives. London: Sage Publications.

Robertson, J., and C. Bond. 2005. Being in the university. In Reshaping the university: New relationships between research, scholarship and teaching, ed. R. Barnett, 79-91. Maidenhead, UK: Society for Research into Higher Education and Open University Press.

Russell, C. 2003. ITET interim evaluation report. Sydney, Australia: University of New South Wales.

Russell, C. 2005. Disciplinary patterns in adoption of educational technologies. Paper presented at 'Exploring the frontiers of e-learning: borders, outposts and migration', Association for Learning Technology Conference, September 6-8, in Manchester, UK.

Russell, C. 2008. E-learning adoption in a campus university as a complex adaptive system: Mapping lecturer strategies. PhD diss., University of Leicester, UK.

Russell, C., and A. Lee. 2005. The Innovative Teaching and Educational Technology (ITET) fellowship: Cultivating communities of practice in learning and teaching. Paper presented at 'Exploring the frontiers of e-learning: Borders, outposts and migration', Association for Learning Technology Conference, September 6-8, in Manchester, UK.

Salmon, G. 2001. Approaches to researching teaching and learning online. In Networked Learning, ed. C. Steeples and C. Jones, 195-212. London: Springer-Verlag.

Senge, P., A. Kleiner, C. Roberts, R. Ross, and B. Smith. 1994. The fifth discipline fieldbook: Strategies and tools for building a learning organization. London: Nicholas Brealey.

SFC. 2006. Developing a new strategy. Edinburgh, UK: Scottish Funding Council.

Sharpe, R., G. Benfield, G. Roberts, and R. Francis. 2006. The undergraduate experience of blended e-learning: A review of UK literature and practice. York, UK: Higher Education Academy. 
Stacey, R. 2005. The activity of leading in organisations: The reflective and the neurotic. Mt Eliza Business Review 7, no. 2: 10-15.

Trigwell, K., and S. Shale. 2004. Student learning and the scholarship of university teaching. Studies in Higher Education 29, no. 4: 523-36.

Trowler, P., and A. Cooper. 2002. Teaching and learning regimes: Implicit theories and recurrent practices in the enhancement of teaching and learning through educational development programmes. Higher Education Research \& Development 21, no. 3: 221-40.

UNSW. 2007. UNSW scores top marks for teaching. UNSW 2007. http://www.unsw.edu.au/ news/pad/articles/2007/oct/Top_marks.html.

Uys, P., J. Buchan, and L. Ward. 2006. Developing digitally enhanced blended learning: A comparative study of Australian Universities. Paper presented at Australian Society for Computers in Learning in Tertiary Education Conference, December 3-6, in Sydney, Australia.

van Fenema, P.C. 2005. Collaborative elasticity and breakdowns in high reliability organizations: Contributions from distributed cognition and collective mind theory. Cognition, Technology \& Work; London 7, no. 2: 134-40.

Varela, F., and H. Maturana. 1972. Mechanism and biological explanation. Philosophy of Science 39, no. 3: 378-82.

Wenger, E., R. McDermott, and W.M. Snyder. 2002. Cultivating communities of practice: A guide to managing knowledge. Boston, MA: Harvard Business School Press.

Wilson, K., and C. Russell. 2003. The first year physics diary project. Paper presented at Australian Society for Computers in Learning in Tertiary Education Conference, December $7-10$, in Adelaide, Australia.

Zuber-Skerritt, O.Y.T. 1992. Action research in higher education: Examples and reflections. London: Kogan Page. 